\title{
Correlation Among Volumetric Conductivity, Electrical Threshold Field and Compensation Plots by Oxidation Induction Time on LDPE/CB Composites
}

\author{
Adhemar Ruvolo Filho ${ }^{\text {a**, Aparecido Junior de Menezes }}{ }^{\mathrm{a}}$, Paulo Sergio do Nascimento Scarpa ${ }^{\mathrm{b} \dagger}$ \\ ${ }^{a}$ Departamento de Química, Universidade Federal de São Carlos - UFSCar \\ São Carlos - SP, Brazil \\ ${ }^{\mathrm{b}}$ Unidade de Tecnologia em Polímeros e Dielétricos, \\ Instituto de Tecnologia para o Desenvolvimento \\ Curitiba - PR, Brazil
}

Received: January 23, 2008; Revised: April 25, 2008

\begin{abstract}
The thermodynamic compensation effect plot derived from Eyring rate process theory was applied to the thermal and UV ageing of LDPE/Carbon Black composites containing commercial carbon black (CB) and carbon black surface oxidized with nitric acid. Correlations were tested among compensation effect, electrical threshold field and volumetric electrical conductivity. Compensation plots from OIT measurements correlate with thermal and UV ageing effect on activation $\Delta \mathrm{S}$ and $\Delta \mathrm{H}$ values, giving a good linear correlation for all samples studied. The relative changes in dc conductivity and electrical threshold field are consistent with the OIT compensation plot, demonstrating that this analysis can be used to monitor LDPE/CB composite degradation under thermal or UV ageing. It can also be used to evaluate, quite accurately, the effect of oxidizing the surface of the $\mathrm{CB}$ on the electrical properties (dc conductivity and electrical threshold field) of the LDPE/CB composites.
\end{abstract}

Keywords: LDPE, Carbon black, compensation plots, OIT, volumetric conductivity, electrical threshold field

\section{Introduction}

Currently, polyethylene, in either its low-density form (LDPE) or especially its cross-linked form (XLPE), is one of the most widely used materials in underground distribution electric cables. There is an increasing interest in developing techniques to diagnose the operating state and predict the remaining life of electrical power equipment in service. Specifically, in Brazil, the need for such techniques is particularly important, due to the intense ultraviolet (UV) radiation, high temperature, and amount of rainfall.

Some researchers ${ }^{1-4}$ have suggested that the ageing mechanism in polyethylene subjected to continual ac electrical stress in a humid environment involves the diffusion of injected ionic species and subsequently the build up of local space charges. Normally, for electrical ageing test conditions, an ac field of about $6 \mathrm{kV} \cdot \mathrm{mm}^{-1}$ has been used for an extended period of time $\mathrm{e}^{5,6}$. However, structural degradation, mainly due to UV radiation, can lead to electrical discharges in the bulk polymer and on its surface, reducing its lifetime, and carbon black (CB) filler has been incorporated into the polyethylene (PE) matrix, which it protects efficiently against UV radiation. The content, as well the distribution or dispersion, of the CB plays an important role in the volumetric conductivity of these $\mathrm{PE} / \mathrm{CB}$ composites.

Montanari ${ }^{7}$ pointed out that a life model which describes the mechanisms of insulation degradation due to the presence of space charges is based on the assumption that even if the applied ac electric field is not large enough to inject hot electrons capable to breaking inter and/or intra-molecular bonds, the trapped charges are responsible for local storage of electromechanical and electrostatic energy which may favour degradation reactions by lowering an activation barrier. This occurs above a certain level of ac electric field, denominated the threshold field, which can be seen as the lowest electrical ageing threshold for insulating polymers. Obviously this threshold field depends strongly on the material and its processing history. An

*e-mail: adhemar@power.ufscar.br

$\dagger$ in memoriam investigation of this threshold may be of fundamental importance when correlated with the possible contribution of the $\mathrm{CB}$ aggregates to the properties of the LDPE/CB composites, since working at electric stresses below the threshold could mean prolonging the life with regard to electrical ageing.

The ageing phenomenon in polymeric insulation materials involves a multitude of effects acting sinergically, making their analysis as separate factors very challenging and unrealistic. The DSC-OIT or TGA-OIT measurements are widely used to determine the so-called oxidative induction time (OIT), which is a measure of the material's oxidative stability. As a matter of fact, the oxidative stability of polymer insulation depends on many factors, some of which may be induced by ageing, such as increased concentration of oxidative by- products, decrease of antioxidants, synergic or antagonistic interactions between antioxidants, UV stabilizers and carbon black, cold crystallization, and water absorption. Then, it would be expected that changes in the polymer insulation oxidative stability may reflect its operating conditions, making the OIT measurement a possible diagnostic control tool. The main advantage of this technique is its high sensivity and ability to yield reliable results with a very small specimen sizes, 1-15 mg.

As pointed out by Montanari et al. ${ }^{8}$, the diagnostic power of the DSC-OIT measurement is improved significantly when the test results are analysed according to Eyring rate theory and displayed on the so-called compensation plot (activation entropy, $\Delta \mathrm{S}$, plotted as a function of the activation enthalpy, $\Delta \mathrm{H})^{9}$.

In this paper, TGA measurements of OIT of LDPE/CB composites were made and displayed in the compensation plot and correlated with the electrical threshold field and electrical volumetric conductivity. For one set of samples, before processing the polymer composite, the surface of the carbon black was oxidized with nitric acid. A set of 
commercial samples of virgin LDPE and LDPE/CB composite were used as reference materials.

\section{Experimental}

\subsection{Raw materials}

Two types of commercial sheets of LDPE, $60 \mu \mathrm{m}$ thickness, were obtained from UNION CARBIDE, the first pure LDPE and the second a composite material with being around 3\% carbon black filler. Also powdered LDPE MN 379 from POLIOLEFINAS (Brazil) was used to prepare composite materials with previously surface-treated carbon black N 220 from UNION CARBIDE.

\subsection{Treatment of Carbon Black $(C B)$}

CB N 220 (UNION CARBIDE) was mixed with concentrated nitric acid in the proportion $\mathrm{HNO}_{3} / \mathrm{CB}$ of $7: 1 \mathrm{w}$ : w, and the suspension was refluxed for 4 hours at $100{ }^{\circ} \mathrm{C}$ to promote surface oxidation of the CB. After that the suspension was allowed to settle, decanted and filtered and the $\mathrm{CB}$ was thoroughly rinsed with distilled water to ensure that all traces of acid were removed. Finally, the $\mathrm{CB}$ was oven-dried in air at $50{ }^{\circ} \mathrm{C}$ for 4 days.

\subsection{LDPE/ Carbon Black composite}

Polymer composites of LDPE MN 379 with $3 \%$ (w/w) CB were prepared in a batch mixer equipped with six shoulder blades on a horizontal steel axle. The melting was promoted by viscous dissipation of energy as a consequence of the high shear rate (blades rotating near $4000 \mathrm{rpm}$ ). The mixing time was controlled by monitoring the current consumption. The end-point was defined as 1.0 minute after the current passed through a maximum that corresponds to the region of wet-out of the filler or to the region of maximum temperature, as mixing occurs.

\section{Characterization}

\subsection{Thermal measurements}

Differential scanning calorimetric (DSC) spectra were recorded with a DuPont DSC 2010 TA calorimeter with resolution of $1 \mu \mathrm{W} \cdot \mathrm{mg}^{-1}$, and precision of $1 \%$, with a maximum base-line background noise of $0.5 \mu \mathrm{W} \cdot \mathrm{mg}^{-1}$. The instrument was calibrated against 3 different metal standards ( $\mathrm{In}, \mathrm{Sn}$ and $\mathrm{Pb}$ ). All measurements were made at heating rate $10{ }^{\circ} \mathrm{C} / \mathrm{min}$ from $30{ }^{\circ} \mathrm{C}$ up to $300{ }^{\circ} \mathrm{C}$, on $10 \mathrm{mg}$ of sample in the form of a disc ( $5 \mathrm{~mm}$ of diameter), in a dynamic $\mathrm{N}_{2}$ atmosphere flowing at $75 \mathrm{~cm}^{3} / \mathrm{min}$.

Thermo-gravimetric analysis (TGA) was recorded with a DuPont TGA $2050 \mathrm{TA}$ analyser of resolution $0.2 \mu \mathrm{g}$. All measurements were made at heating rate of $10{ }^{\circ} \mathrm{C} / \mathrm{min}$, from $30^{\circ} \mathrm{C}$ up to $700{ }^{\circ} \mathrm{C}$, on $7 \mathrm{mg}$ of sample in disc form ( $5 \mathrm{~mm}$ diameter), under $\mathrm{N}_{2}$ or $\mathrm{O}_{2}$ flowing at $10 \mathrm{~cm}^{3} / \mathrm{min}$.

\subsection{Electrical measurements}

Press-moulded films of the LDPE/CB composite, denominated sample LDPECBTS, and commercial sheets of LDPE, with and without carbon black, respectively denominated samples LDPECBC and LDPEBR, all with average thickness $60 \mu \mathrm{m}$ were used for conduction current measurement. Before all tests the samples were short-circuited for 24 hours at room temperature to avoid after- effect phenomena. After that, electrodes of diameter $15 \mathrm{~mm}$ were prepared by sputtering aluminium on both surfaces of disc-shaper polymer film samples. Charging was performed by a three terminal cell, at different levels of constant dc voltage with a Hewlett Packard HP
Model 6521A DC power supply, at room temperature for period of 700 minutes. Discharge current was than monitored with a Keithley Model 617 electrometer and the value obtained after 10 minutes was used to calculate the volumetric conductivity.

\subsection{Scanning Electronic Microscopy (SEM).}

The distribution and the degree of dispersion of carbon black aggregates in the LDPE/CB composite materials were analysed in SEM DSM 940 Zeiss microscopy images of the liquid-nitrogen fracture surface of polymer samples.

\subsection{Ageing experiments}

The LDPE and LDPE/CB composite films were subjected to three ageing treatments:

TA90: immersion in water at $90^{\circ} \mathrm{C}$ for 7 days;

TS90: oven-dried in air at $90{ }^{\circ} \mathrm{C}$ for 7 days; and

UV300: UV radiation in a specially designed cell. Inside the cell, a low-pressure mercury G10T5172 lamp $\left(\right.$ GERMITEC $\left.^{\circledR}\right)$ of $16 \mathrm{~W}$ emitted ultra-pure UV light, main emission line $254 \mathrm{~nm}$ corresponding to an energy of $5.44 \mathrm{eV}$ (equivalent to an UV emission of $1.85 \mathrm{x}$ $10^{-4} \mathrm{eV} / \mathrm{s}$ from the mercury lamp of $16 \mathrm{~W}$ ). The ageing process was carried out at $30^{\circ} \mathrm{C}$, in air, with the samples located $50 \mathrm{~mm}$ from the UV radiation source, for up to 300 hours.

TGA-OIT measurements: To measure the OIT, the following methodology was used: i) the TGA was performed at 5 different heating rates $\left(1,5,10,15,20\right.$ and $\left.30^{\circ} \mathrm{C} / \mathrm{min}\right)$; ii) taking an isopleth $(2 \%$ of lost weight in the degradation region of the TG curve), from the curves obtained at each heating rate, the corresponding onset oxidation temperature(OOT) was obtained; iii) from a plot of oxidation temperature at $2 \%$ loss of weight vs. the heating rate, it is possible to extrapolate to a reference oxidation temperature (To) for zero heating rate $^{10}$, the values obtained being shown in Table 1 and a typical curve in Figure 1; and iv) for each sample, the OIT measurements were made by pre-selecting 4 temperatures: two of them 5 and $10^{\circ} \mathrm{C}$ below To and the other two 5 and $10{ }^{\circ} \mathrm{C}$ above To. The OIT measurements were made, as in Statherpoulos et al. ${ }^{11}$, by placing the specimen in a TGA cell enclosed in the TGA furnace. Inert gas (nitrogen) was passed through the cell at a rate of $90 \mathrm{~mL} / \mathrm{min}$. The cell was then heated at a constant rate of $20^{\circ} \mathrm{C} / \mathrm{min}$ to a pre-selected temperature. After the temperature had stabilized the inert gas was replaced by dry oxygen flowing at the same rate. The TGA furnace was maintained at the same temperature until the output signal (sample weight) indicated oxidation.

According to the Eyring thermodynamic rate theory, the time $t$ required to proceed from the original to the final state of an activated process can be expressed as ${ }^{9}$ :

$$
\mathrm{t}=\mathrm{h} / \mathrm{kT} \exp (\Delta \mathrm{G} / \mathrm{kT})=\mathrm{h} / \mathrm{kT} \exp (-\Delta \mathrm{S} / \mathrm{k}) \exp (\Delta \mathrm{H} / \mathrm{kT})
$$

Table 1. Reference oxidation temperature $\left(\mathrm{T}_{\mathrm{o}}\right)$

\begin{tabular}{lc}
\hline \multicolumn{1}{c}{ Samples } & $\mathrm{T}_{\mathrm{o}}\left({ }^{\circ} \mathrm{C}\right)$ \\
\hline LDPEBR original & 200.5 \\
LDPEBR TS90 & 183.5 \\
LDPEBR TA90 & 228.0 \\
LDPEBR UV300 & 200.0 \\
LDPECBC original & 234.3 \\
LDPECBC TS90 & 204.5 \\
LDPECBC TA90 & 223.4 \\
LDPECBC UV300 & 241.0 \\
LDPECBTSoriginal & 199.1 \\
LDPECBTS TS90 & 188.0 \\
LDPECBTS TA90 & 214.5 \\
LDPECBTSUV300 & 206.4 \\
\hline
\end{tabular}




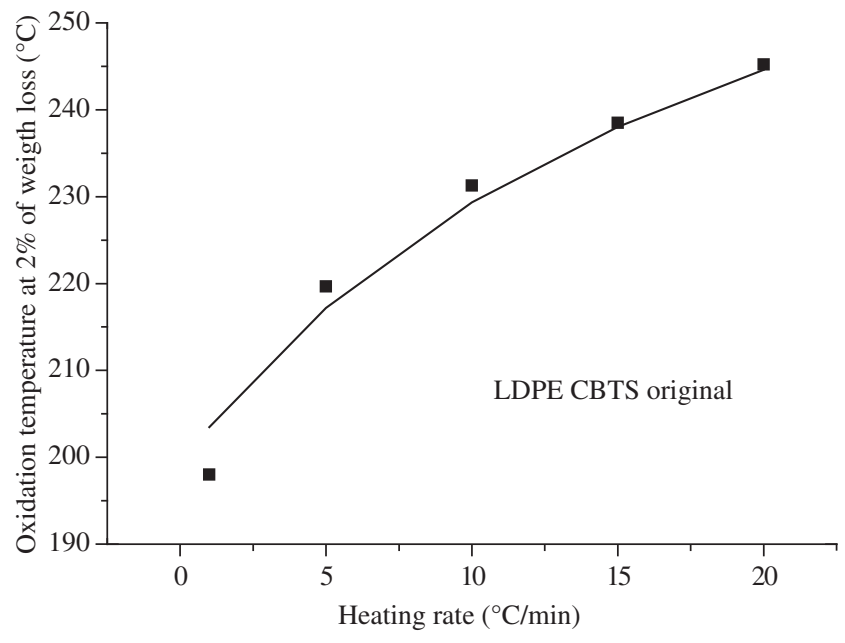

Figure 1. Typical curve of OOT as a function of heat rate.

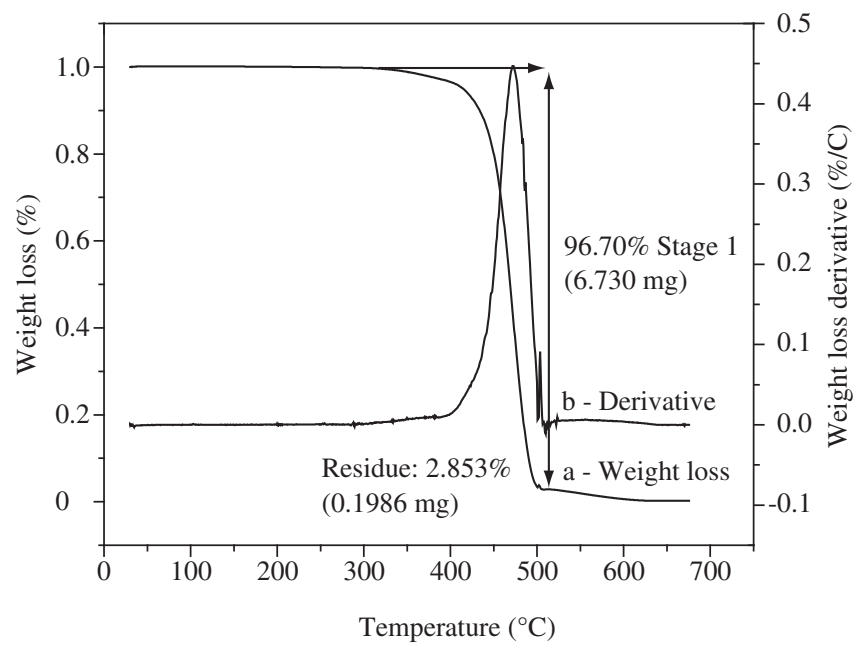

(a) where, $\mathrm{h}$ and $\mathrm{k}$, are the Planck and Boltzmann constants and $\Delta \mathrm{S}$ and $\Delta \mathrm{H}$ the entropy and enthalpy of activation during the OIT measurements. From Equation 1, a relationship between $\log (\mathrm{t} . \mathrm{T})$ and 1/T can be derived:

$$
\log (\mathrm{t} . \mathrm{T})=\left(\log \mathrm{h} / \mathrm{k}-\Delta \mathrm{S} / \mathrm{k}^{\prime}\right)+\Delta \mathrm{H} / \mathrm{k}^{\prime} \mathrm{T}=\mathrm{A}+\mathrm{B} \cdot 1 / \mathrm{T}
$$

where $\mathrm{k}^{\prime}=\mathrm{k} / \log \mathrm{e} \sim 2.3 \mathrm{k}$.

Letting $\mathrm{t}=\mathrm{OIT}$, determined from the experiments carried out at the different temperatures, A and B can be estimated by applying regression analysis to the experimental results plotted on the Eyring coordinates $(\log (\mathrm{t} . \mathrm{T}))$ and $(1 / \mathrm{T})$. Thus, from $\mathrm{A}$ and $\mathrm{B}$ the $\Delta \mathrm{S}$ and $\Delta \mathrm{H}$ can be calculated. The existence of the compensation effect can be verified if a linear relationship exists between $\Delta \mathrm{S}$ and $\Delta \mathrm{H}$.

\section{Results and Discussion}

Figure 2 shows the TGA analysis and carbon black content (residue) in the LDPE/CB composites. Both commercial and prepared samples gave practically the same values, 2.85 and $2.93 \%$ respectively.

Figure 3 shows, for comparison, SEM micrographs of the LDPE/ $\mathrm{CB}$ composites. As can be seen and estimated, the carbon black

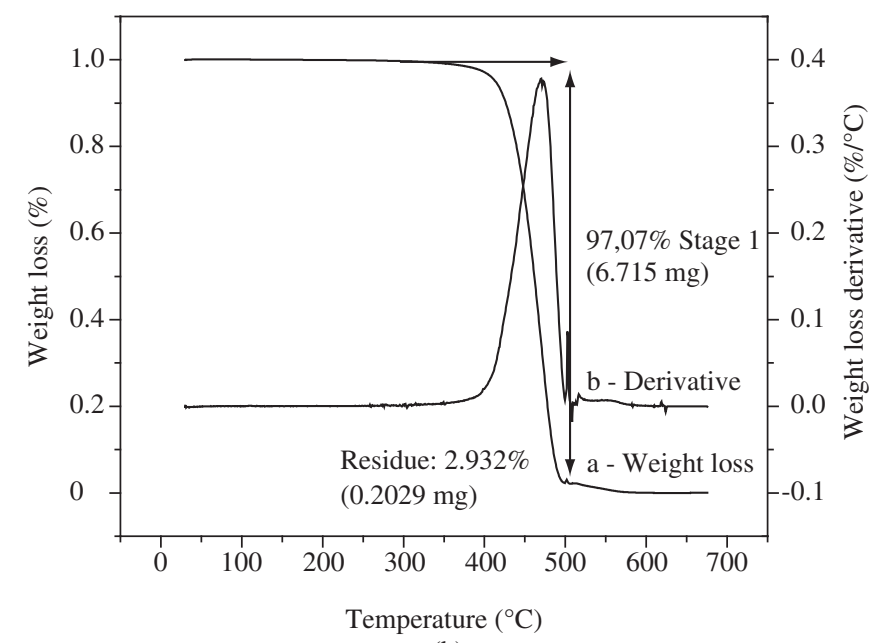

(b)

Figure 2. a) TG curve of LDPE CBC sample; and b) TG curve of LDPE CBTS sample.

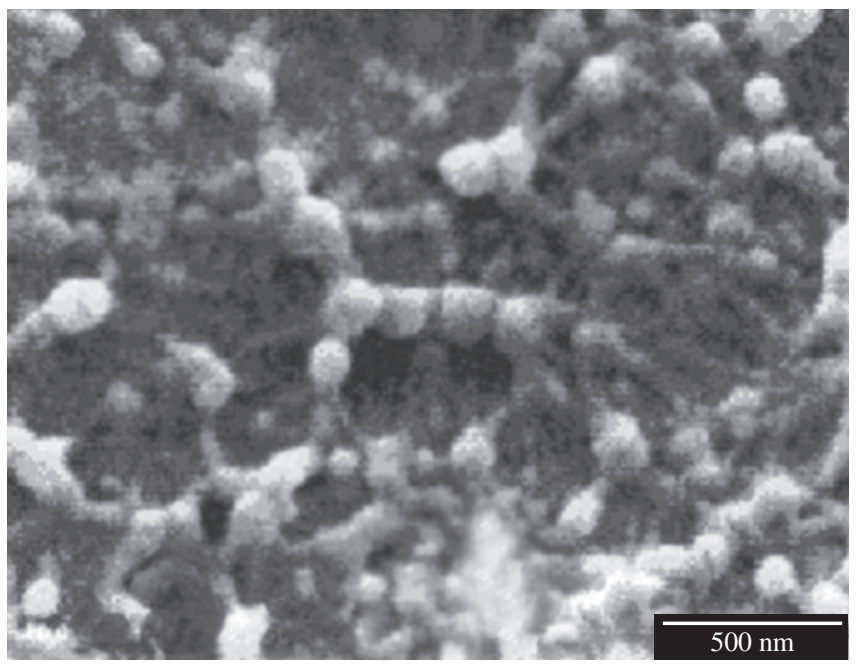

(a)

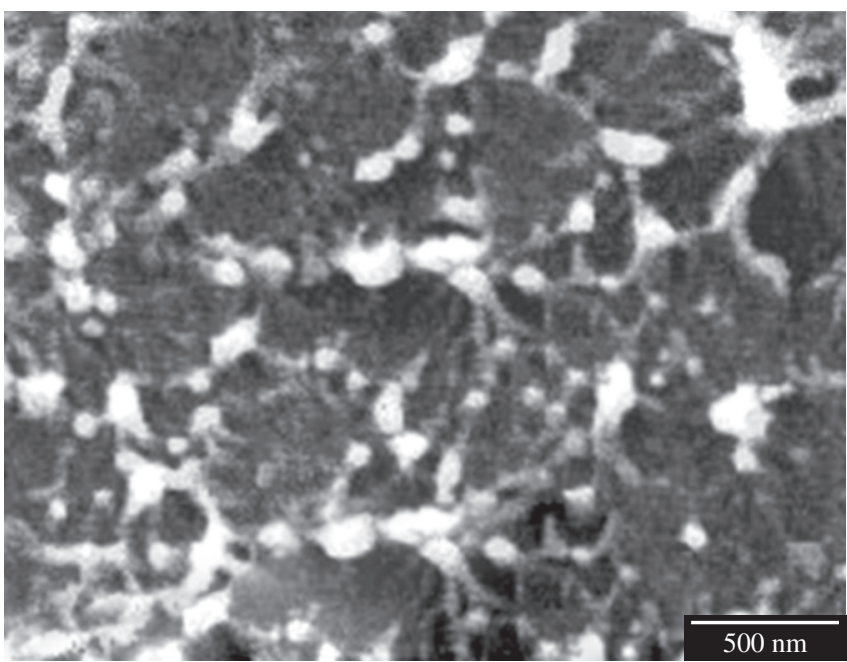

(b)

Figure 3. SEM micrographs of samples: a) LDPE CBC and b) LDPE CBTS with CB aggregate sizes of $210 \mathrm{~nm}$ and $100 \mathrm{~nm}$ respectively. 
aggregate has dimensions of the order $100 \mathrm{~nm}$ and $200 \mathrm{~nm}$ for the samples LDPECBTS and LDPECBC respectively. Also, note that the distribution and dispersion of the $\mathrm{CB}$ aggregates are better in the sample LDPECBTS, suggesting that processing under high shear has a positive effect on these properties.

Figures 4, 5 and 6 show the DSC thermograms for the original and aged LDPEBR, LDPECBC and LDPECBTS samples.

Comparing the DSC melting behaviour in Figures 4-6, the following events can be observed:

a) For all samples treated at $90{ }^{\circ} \mathrm{C}$, in the presence of water (TA90), two endothermic events: a broad peak, like a shoulder extending from $95-105^{\circ} \mathrm{C}$ and a sharp peak at about $110^{\circ} \mathrm{C}$. These results suggest that water can act as a plasticizer, inducing a recrystallization during the thermal treatment at $90{ }^{\circ} \mathrm{C}$, and generating two populations of crystals of different size;

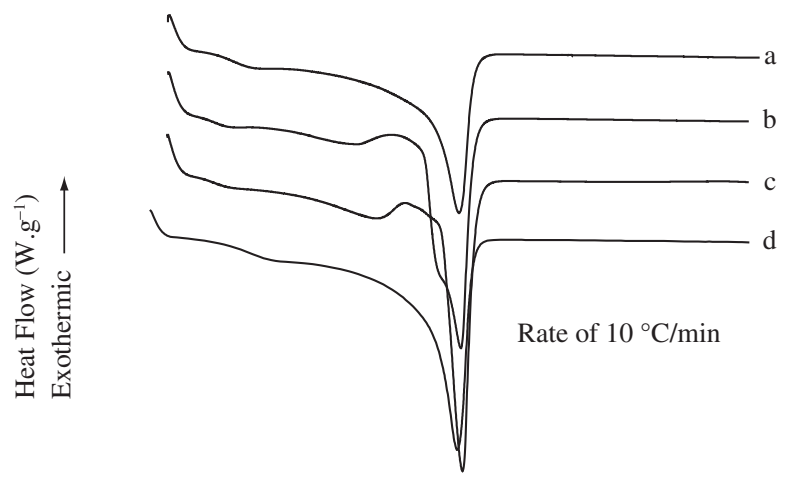

\begin{tabular}{cccccccccccc}
\hline 0 & 20 & 40 & 60 & 80 & 100 & 120 & 140 & 160 & 180 & 200 & 220 \\
Temperature $\left({ }^{\circ} \mathrm{C}\right)$
\end{tabular}

$$
\begin{aligned}
& \text { a - ORIG } \Delta \mathrm{H}_{\mathrm{f}}=80.05 \mathrm{~J}_{\mathrm{g}}{ }^{-1} \\
& \text { b - TA90 } \Delta \mathrm{H}_{\mathrm{f}}=77.37 \mathrm{J.g}^{-1} \\
& \text { c - TS90 } \Delta \mathrm{H}_{\mathrm{f}}=66.99 \mathrm{~J} . \mathrm{g}^{-1} \\
& \text { d - UV300 } \Delta \mathrm{H}_{\mathrm{f}}=139.0 \mathrm{~J} . \mathrm{g}^{-1}
\end{aligned}
$$

Figure 4. DSC thermogram for the LDPE BR sample.

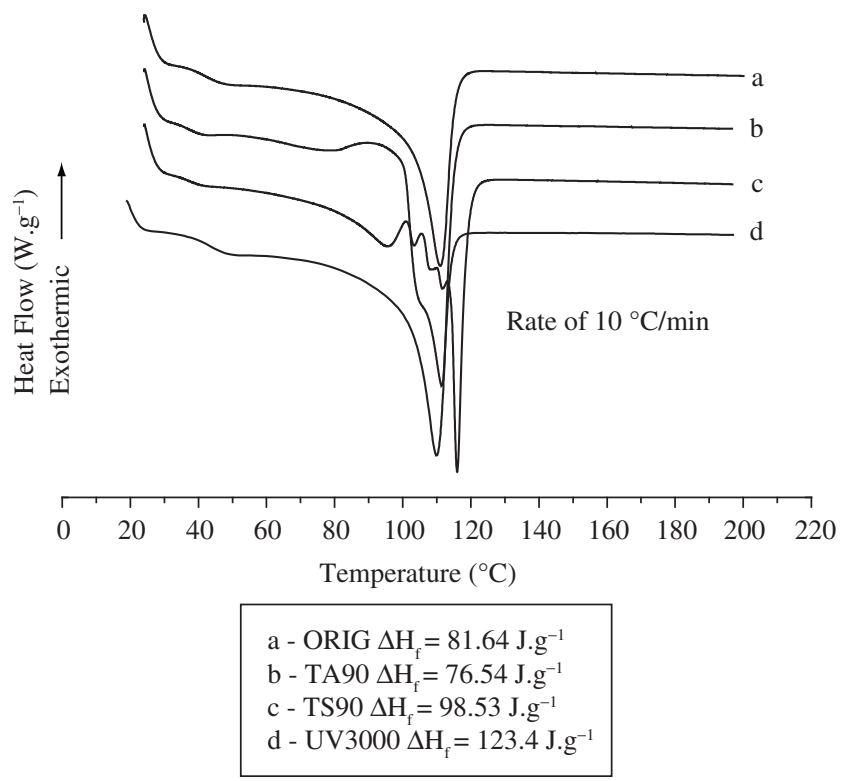

Figure 5. DSC thermogram for the LDPE CBC sample. b) For all samples treated at $90{ }^{\circ} \mathrm{C}$, in the absence of water (TS90), the melting behaviour for the samples BR and CBTS is the same, showing a single sharp endothermic peak at about $110^{\circ} \mathrm{C}$, whereas for the sample CBC, there is a sharp peak at about $115^{\circ} \mathrm{C}$ and multiple small endothermic peaks extending from $70-110^{\circ} \mathrm{C}$ which can be attributed to polymorphic behaviour. In the same way, a broad isotherm peak appear in the curves $4 b, 4 c, 5 b, 6 b$ and $6 c$ extending from $60-95{ }^{\circ} \mathrm{C}$.

Taking into account that the $\mathrm{CBC}$ showed a poor distribution and dispersion and larger aggregates, as can be seen by comparing Figures $3 \mathrm{a}$ and $3 \mathrm{~b}$, it could be postulated that if this phenomenon can reduce the reptation movement of the polymer chain segments, then during ageing at $90{ }^{\circ} \mathrm{C}$ the recrystallization process takes place, but results in a wide distribution of crystals with different lamellar sizes that, during fusion, exhibit a polymorphic behaviour.

c) For all UV-irradiated samples, the melting behaviour seems to be the same, with just one endothermic peak at about $110^{\circ} \mathrm{C}$, but broader than that observed for the original sample at the same melting temperature.

These results confirm the effect of UV radiation on the mechanism of chain scission commonly observed in LDPE. The broadening observed in the melting endothermic peak indicates that during the 300 hours of UV time exposure, the LDPE can recrystallize, giving rise to a large population of crystals of different size, that corroborates with the higher melting enthalpy values show in Figures 4-6.

Figure 7 shows examples of OIT data plotted in the Eyring coordinates.

The activation $\Delta \mathrm{S}$ vs. $\Delta \mathrm{H}$ compensation plot, shown in Figure 8 , collects the data for all samples analysed after all the ageing conditions described in the experimental section. These components of activation energy are calculated from the slopes and intercepts of the linear plots of OIT data represented in Eyring coordinates, as shown in Figure 7.

It can be observed in Figure 8 that the points representing the diverse ageing conditions can be fitted by linear regression to one compensation line with a coefficient of determination $\left(\mathrm{r}^{2}\right)$ of 0.95 , giving a reasonable linear fit. The position of data points on the compensation plots can move along the compensation line, demon-

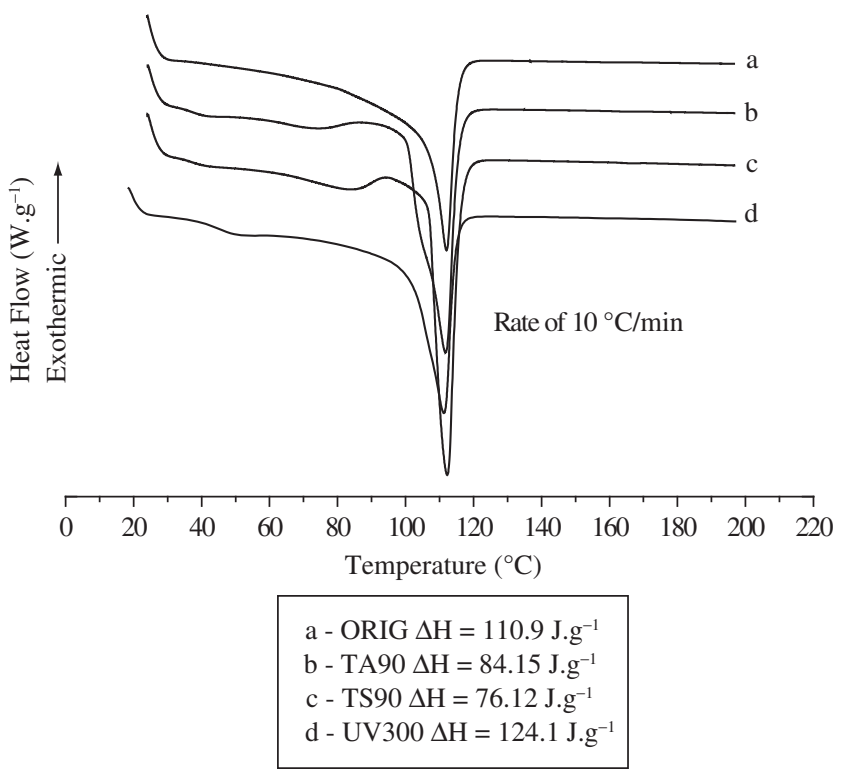

Figure 6. DSC thermogram for the LDPE CBTS sample. 


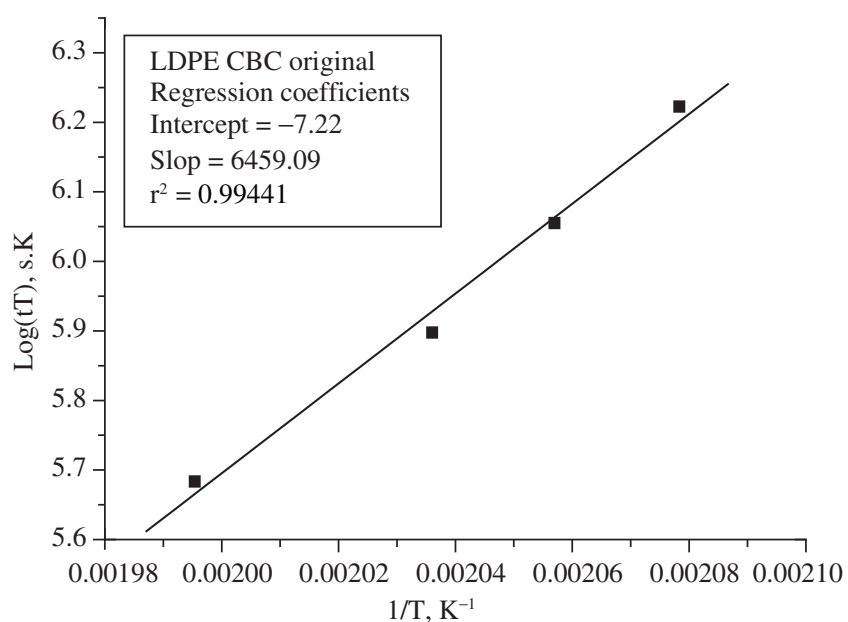

(a)

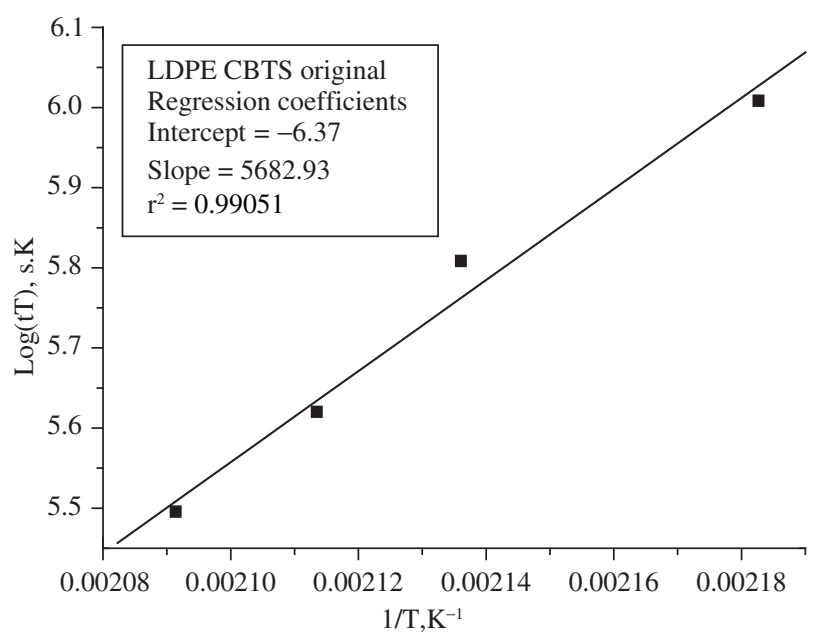

(b)

Figure 7. Examples of OIT data plotted in Eiring coordinates: a) original $\mathrm{CBC}$ sample and b) original CBTS sample.

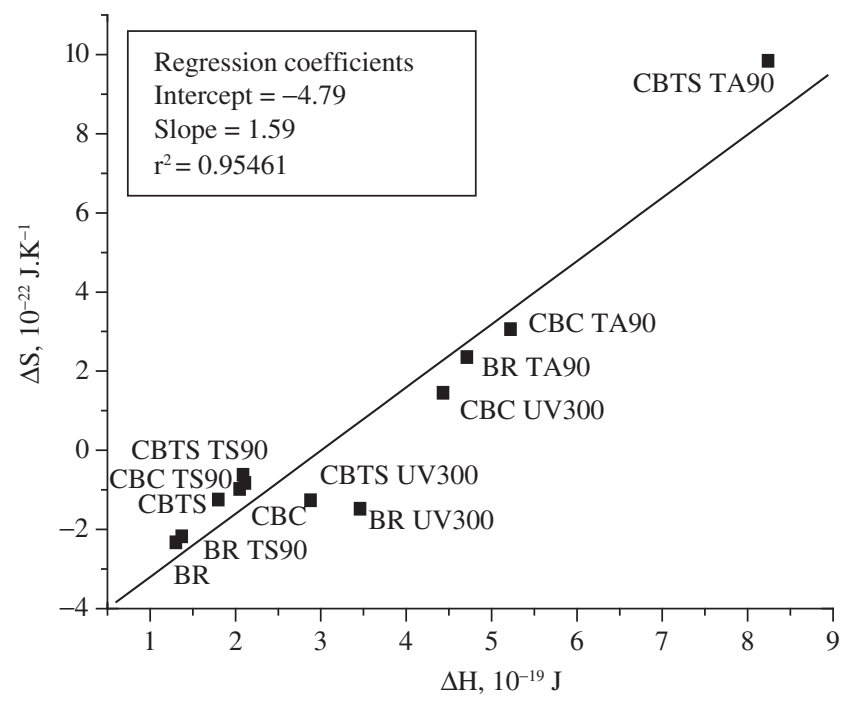

Figure 8. The $\Delta \mathrm{S}$ vs. $\Delta \mathrm{H}$ compensation plot for all the samples, before and after ageing treatments. strating the severity of the ageing conditions. Thus, with respect to the unaged samples, if the points move towards lower negative $\Delta \mathrm{S}$ and $\Delta \mathrm{H}$ values, ageing seems to be accelerated. On the other hand, if the points move to higher positive $\Delta \mathrm{S}$ and $\Delta \mathrm{H}$ values it seems that the samples retain/or augment their original properties. Hence, from the results shown in Figure 8, the samples: CBC TA90, CBC UV300 and BR TA90, can be considered as having their original properties enlarged, and, CBTS TA90 as having its original properties markedly enhanced. This result is consistent with the thermal behaviour shown in Figures 5b, 5d, 4b and 6b, suggesting that the compensation plot reflects changes in the properties of a material, caused by thermal or UV ageing. Specifically, for the samples analysed, thermal ageing in the presence of water may eliminate some inhomogeneous stress frozen into the polymer matrix, which can be generated during processing, and induce its crystallization. Therefore it is relevant that, for the sample CBTS TA90, the surface treatment of the carbon black, which reduces its aggregate size, can contribute, to an increase in crystallinity, reducing the oxygen uptake taking place during the OIT measurements.

Another consideration can be made by comparing the result for the sample CBC UV300 with the sample CBTS UV300. The commercial samples, beyond carbon black, contain primary and secondary additives to prevent thermo-oxidation whereas our CBTS sample is free of these additives. Therefore, as pointed out by Peña et al. ${ }^{12,13}$, the nature of the CB plays an important role in controlling its performance as a stabilizing agent alone, as well as its interactions with light stabilizers and antioxidants, via adsorption-desorption processes as well as other chemical interactions. Thus, if there is a synergistic interaction between the additives and carbon black, it can improve the thermal behaviour of the LDPE matrix during the OIT measurements.

At this point it is important to consider some correlations between the electrical properties measured (presented in Table 2) and the $\Delta \mathrm{H}$ values.

Figures 9 and 10 shown plots of the relative changes in dc volumetric conductivity $=\sigma / \sigma_{\mathrm{o}}$, and electrical threshold field $=\mathrm{E}_{\mathrm{th}} / \mathrm{E}_{\mathrm{tho}}$, against $\Delta \mathrm{H}$ values, where $\sigma_{\mathrm{o}}$ and $\mathrm{Et}_{\mathrm{ho}}$ are the values before ageing.

In Figure 9, it can be observed that the same sample tests that result in more positive $\Delta \mathrm{S}$ values after ageing, as can be seen in Figure 8 , give relative changes in dc volumetric conductivity lower than unity and higher $\Delta \mathrm{H}$ values. Furthermore, in Figure 10, it can be observed that these samples also exhibit increases around 20-30\%

Table 2. Electrical properties measured for the samples after and before ageing conditions.

\begin{tabular}{lcc}
\hline \multicolumn{1}{c}{ Samples } & $\begin{array}{c}\sigma, \\
10^{-19} \text { S.mm }\end{array}$ & $\mathrm{E}_{\mathrm{th}}, \mathrm{kV} . \mathrm{mm}^{-1}$ \\
\hline LDPEBR original & 18 & 8.0 \\
LDPEBR TS90 & 2.2 & 6.0 \\
LDPEBR TA90 & 6.8 & 8.0 \\
LDPEBR UV300 & 2.9 & 8.0 \\
LDPECBC original & 77 & 8.0 \\
LDPECBC TS90 & 140 & 6.0 \\
LDPECBC TA90 & 1.9 & 10 \\
LDPECBC UV300 & 1.5 & 10 \\
LDPECBTS original & 0.66 & 8.5 \\
LDPECBTS TS90 & 2.9 & 12 \\
LDPECBTS TA90 & 0.31 & 10 \\
LDPECBTSUV300 & 1.6 & 8.0 \\
\hline
\end{tabular}




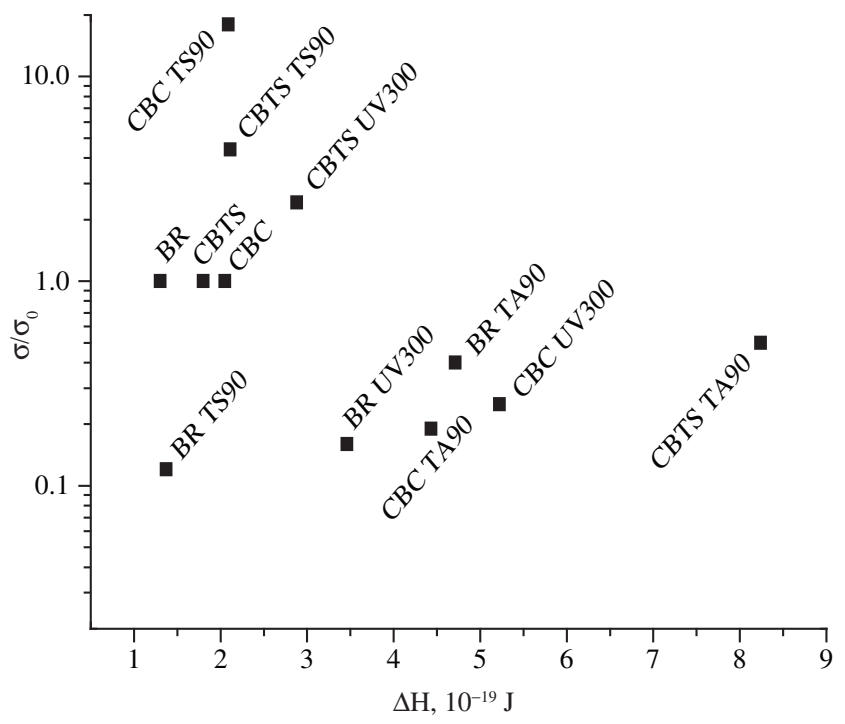

Figure 9. The $\sigma / \sigma o$ vs. $\Delta \mathrm{H}$ plot for all the samples,before and after ageing treatments.

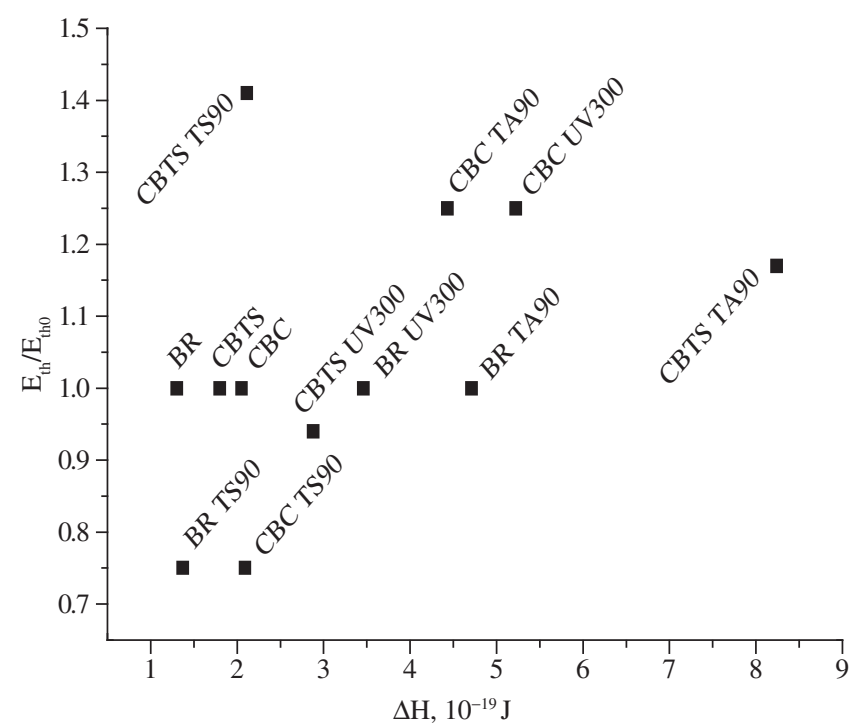

Figure 10. The Eth/Etho vs. $\Delta \mathrm{H}$ plot for all the samples, before and after ageing treatments.

in relative electrical threshold field. One surprise is the increase of around $40 \%$, observed for the sample CBTS TS 90 . Therefore, it is important to take into account that the value obtained for the relative change of volumetric conductivity, for this sample, was four times higher than that of the original sample.

Carbon black consists of spherical, so-called primary particles. The basic buildings blocks of these particles are graphene layers, orientated concentrically. While these graphene layers can contain chemical discontinuities, in spite of these imperfections, the electrical conductivity inside the particle is certainly relatively high. Some of the graphene layers can be extended over two adjacent particles ${ }^{14}$ and these overlapping graphene layers can ensure a relatively high conductivity between particles of the same aggregate. Hence, the most important factor contributing to the electrical resistance is certainly the interface between particles of different aggregates. It may thus be postulated that the chemical nature of the carbon black surface strongly influences the electrical conductivity at this interface and that the distribution, dispersion and size of the carbon black aggregates are of crucial importance. The surface treatment of the carbon black with nitric acid increases the fraction of hydroxyl and other oxygencontaining groups. These groups, covering the surface of the carbon black particles, can raise the potential barrier to electrons moving from one aggregate to another or forms an insulating shield around the particles ${ }^{15}$, so that the electrical conductivity of the carbon black aggregate is diminished by oxidation with nitric acid. This analysis is consistent with the results shown in Table 2, where it can be observed that the volumetric conductivities of all CBTS samples (with exception of CBTS UV300) are lower than those of the commercial CBC samples.

\section{Conclusions}

The dc volumetric conductivity and electrical threshold field of LDPE/CB composites, in which the carbon black had been subjected to oxidative surface treatment, were measured before and after thermal or UV ageing.

Compensation plots derived from OIT measurements showed a correlation with the thermal and UV ageing effect on the values of activation $\Delta \mathrm{S}$ and $\Delta \mathrm{H}$, giving a good linear relation between these thermodynamic parameters for all samples studied.

The relative changes in the dc conductivity and electrical threshold field were consistent with the OIT compensation plot, showing that this analysis can be used to monitor the LDPE/CB composite degradation under thermal or UV ageing. It also can provide, with a good accuracy, a measure of the improving effect of the oxidizing the surface of the carbon black, on the electrical properties ( $\mathrm{dc}$ conductivity and electrical threshold field) measured in LDPE/CB composites.

\section{Acknowledgments}

The authors are grateful to the Conselho Nacional para o Desenvolvimento Científico e Tecnológico do Brasil (CNPq) for financial support for this work.

\section{References}

1. Steenis EF, Krueger FH. Water treeing in polyethylene cables. IEEE Trans. Dielectr. Electr. Insul. 1990; 25(5):989-1028.

2. Fouracre RA, Given MJ, Crichton BH. The effect of alternating electric fields on ion migration in solid dielectrics. J. Phys. C.: Solid State Phys. 1986; 19:1949-1958.

3. Das-Gupta DK, Svatik A, Bulinski AT, Densley RJ, Bamji S, Carlsson DJ. On the nature of AC field aging of cross-linked polyethylene using liquid electrodes. J. Phys. D: Appl. Phys. 1990; 23:1599-1607.

4. Dissado LA, Fothergill JC. Electrical Degradation and Breakdown in Polymers. Wiltshire, UK: Redwood; 1992.

5. Das-Gupta DK, Scarpa PCN. Polarization and dielectric behaviour of AC aged polyethylene. IEEE Trans. Dielectr. Electr. Insul. 1996; 3(3):366-374.

6. Scarpa PCN, Svatik A, Das-Gupta DK. Dielectric spectroscopy of polyethylene in the frequency range of $10^{-5} \mathrm{~Hz}$ to $10^{6} \mathrm{~Hz}$. Polym. Eng. Sci. 1996; 36(8):1072-1081.

7. Montanari GC. The electrical degradation threshold of polyethylene investigated by space charge and conduction current measurements. IEEE Trans. Dielectr. Electr. Insul. 2000; 7(3):309-315.

8. Montanari GC, Motori A, Bulinski AT, Bamji SS, Densley J. Application of oxidation induction time and compensation effect to the diagnosis of HV polymeric cable insulation. IEEE Trans. Dielectr. Electr. Insul. 1996; 3(3):351-360. 
9. Crine JP. A thermodynamic model for the compensation law and its physical significance for polymers. J. Macromol. Sci. 1984; B23:201-219.

10. Ruvolo-Filho A, Sampaio EMV, Marconcini, JM. Determinação da temperatura termodinâmica de início de oxidação. Anais do Encontro Regional de Usuários de Técnicas Termoanalíticas; 2003 Out 20; São Carlos, SP, Brasil: editora USP; 2003.

11. Kyriakou SA, Statherpoulos M, Parissakis GK, Papaspyrides CD, Kartalis CN. Oxidative induction time method based on thermogravimetry for monitoring the restabilization of post-use LDPE. Polym. Degrad. and Stab. 1999; 66:49-53.
12. Peña JM, Allen NS, Edge M, Liauw CM, Valange B. Interactions between carbon black and stabilisers in LDPE thermal oxidation. Polym. Degrad. and Stab. 2001; 72:163-174.

13. Peña JM, Allen NS, Edge M, Liauw CM, Valange B. Studies of synergism between carbon black and stabilisers in LDPE photodegradation. Polym. Degrad. and Stab. 2001; 72:259-270.

14. Hess WM, Herd CR. In: Donnet J, Bansal RC, Wang M, (editors). $2^{\text {nd }}$ ed. Carbon black science and thechnology. New York, USA: Marcel Dekker; 1993.

15. Gang Y, Zhang MQ, Zeng HM. Carbon-black-filled polyolefin as a positive temperature coefficient material: Effect of composition, processing and filler treatment. J. Appl. Polym. Sc. 1998; 70:559-566 